\title{
How the news was made: The Anti-Social Behaviour Day Count, newsmaking criminology and the construction of anti-social behaviour
}

\begin{abstract}
'Newsmaking criminology' is an approach to criminological research characterised by critical engagement with topics being covered by the news media, offering greater engagement with public debate and reflexive critique of the objects of criminological knowledge. Two examples of Brisith criminological researchers taking an identifiable 'newsmaking' approach are discussed in this paper: the Anti-Social Behaviour One Day Count, a 24-hour comprehensive survey of reports of anti-social behaviour carried out in 2003, and the 24-hour Domestic Violence Audit, carried out in 2000. This paper analyses the construction of knowledge of anti-social behaviour through the Day Count, identifying continuities and discontinuities between the Day Count and the Domestic Violence Audit. This leads to a discussion of the strengths and limitations of the 'newsmaking' approach, suggesting that it may serve conservative as well as progressive ends.
\end{abstract}

\section{Keywords}

Anti-social behaviour, chronic crime, domestic violence, newsmaking criminology

\section{Introduction: making the news}

Critical criminological practice faces two recurring problems, with what might seem diametrically opposed solutions. Firstly, engagement with issues of power, knowledge and emancipation demands a level of reflexivity. As Thomas and O'Maolchatha argue, the emancipatory potential of critical criminology derives, at least in part, from its grounding in ideological critique: "the 'truth' of critical criminology ... lies in an ability to transcend, even if not quite to escape, dominant ideas 
and to reshape them in ways that suggest new theoretical insights and empirical directions" (Thomas and O'Maolchatha 1989; quoted in Pavlich 1999: 40). As such, the critique of critical criminology is always to some extent turned on the objects of criminological knowledge and the conditions of production of that knowledge.

At the same time, critical criminologists are faced with wider discourses of crime and criminality shaped by government, police and media interventions. There is a need to engage with these discourses and intervene in continuing public conversation about crime - not only for the satisfaction of demonstrating 'impact' but so as to bring critique to bear on concepts worth criticising, and make critical insights available to a wider public.

Addressing these two problems together is problematic: critical reflection on the received conceptual armoury of criminology can cut away any common vocabulary with which criminologists could intervene in public discourse. Arguably there is a limit to how conceptually critical - and, by extension, how reflexive - critical criminology can afford to be. "The thing that criminology cannot do is deconstruct crime ... To do so would be to abandon criminology to sociology; but more importantly it would involve abandoning the idea of a unified problem which requires a unified response." (Smart 1992: 77). Carol Smart's argument may have been overstated if applied to the academic discipline of criminology: few criminologists regard burglary, terrorism, drug use etc. as 'a unified problem'. Where public engagement is concerned, however, it would clearly impede the conversation if criminologists collectively forswore the word 'crime'.

Critical criminologists appear to face a difficult choice: either submit to the discipline of the marketplace of popularisation and common-sense realism, or retreat to an increasingly shabby ivory tower to play at conceptual clarification. This division - in less caricatural terms, the division between "a criminology that is interested ... in the reflexive sociology of criminological knowledge, and in the testing or transgressing of disciplinary boundaries" and "a criminology that 
has empirical bite and strategic relevance" (Garland and Sparks 2000: 191) - is clearly undesirable; the question is how to resolve it, helping to realise the emancipatory potential of critical criminology by combining reflexivity with public engagement.

An interesting attempt to address questions like these is Gregg Barak's concept of "newsmaking criminology". (It should be noted that Barak does not see himself as working within 'critical criminology' and has expressed scepticism about the value of the phrase (Barak 1994/1995; quoted in Pavlich 1999: 36).) Barak defines newsmaking criminology as "the conscious efforts and activities of criminologists to interpret, influence, or shape the representation of 'newsworthy' items about crime and justice" (Barak 1988; quoted in Barak 2007: 192). Newsmaking criminology is presented as a contributing to the empowerment of oppressed groups and "the development of a progressive politics on law and order, and crime and justice" (Barak 2007: 203), as well to as the reflexive demystification of criminology. Newsmaking criminology is thus associated with an understanding of crime embedded in a broader progressive politics: in Barak's words, "newsmaking criminologists [can] help shape the 'progressive' discourse, language and representation of crime and justice, and ultimately the policies that are adopted and acquiesced to by societies in their 'fights' against crime and injustice." (Barak 2007: 205).

As described by Barak, newsmaking criminology has four key features. It is reactive, promoting academic engagement with the media by applying a criminological focus to issues already constructed as 'newsworthy'. Secondly, it is critical: it "attempts to demystify images of crime and punishment by locating the mass media portrayals of incidences of 'serious' crimes in the context of all illegal and harmful activities" (Barak 2007:192), challenging received concepts of crime. Thirdly, it aims to "facilitate a public policy of 'crime control' based on structural and historical analyses of institutional development" (Barak 2007:192); as such it is sceptical of the capacity of the criminal justice system to control the harms of crime, taking a broader view of the 
phenomenon. Lastly, newsmaking criminology is partisan, calling on criminologists to "eschew notions of alleged value neutrality and 'objectivity'" (Barak 2007: 193).

Reactive, critical, sceptical and partisan, 'newsmaking criminology' criminology responds to existing public concerns about crime, harm and risk; it situates events presented as crime in the context of a broad range of known social harms, some of which have failed to be identified as criminal; it advocates an approach to their control which goes beyond the existing criminal justice system; and it takes the side of the victims of those harms. It brings the twin challenges of reflexivity and public engagement together and addresses them in the same process: intervening in public - and mass media - debate, applying a critical and demystifying perspective to the 'crime' issues under discussion, taking sides in the debate on the basis of open partisanship, and bringing the results of the intervention to bear on the production of knowledge within the academy. Making the news, in this perspective, is also re-making the academic discipline of criminology.

This presentation of newsmaking criminology prompts two questions, which will be addressed using a pair of case studies. The first question is, simply, whether the approach outlined by Barak works: whether it is possible for public engagement to be enriched by the critical attitude characteristic of academic criminology, and for criminology in turn to derive a renewed and clarified sense of partisanship from the engagement. The second is whether the essentially methodological outline given by Barak fully specifies a process which will reliably produce emancipatory criminological knowledge, or whether the approach and methods of 'newsmaking criminology' are adaptable to serve conservative or reactionary purposes - and, if so, how radical 'newsmakers' can ensure that their use of the method has the desired effect.

To investigate these questions, both the 2000 Domestic Violence Audit and the 2003 Anti-Social Behaviour Day Count will be considered as initiatives using "newsmaking criminology" approaches. These two initiatives are comparable in that they both formed part of efforts to direct 
the attention of the public and the criminal justice system to under-recognised harms; both also had reflexive effects on the discipline of criminology, bringing increased salience to the types of offending behaviour which they addressed. The two will be compared in terms of the procedures used, the types of crime knowledge produced and the interests furthered, suggesting some conclusions about how adaptable the "newsmaking" approach may be in practice.

\section{"Nearly every minute of the day": the Domestic Violence Audit}

On 28 September 2000, a group of researchers carried out a 24-hour audit aiming to quantify the incidence of domestic violence and its impact on the workload of public and voluntary services. The main source of data for the Domestic Violence Audit was calls for service to the police forces of England and Wales; the Audit established that domestic violence accounts for around 3\% of such calls (Stanko 2001: 219). This figure represents "over 1300 police calls a day": "a call ... nearly every minute of the day" or "over 570,000 each year" (ibid.) Police service call data was supplemented by statistics from Victim Support, giving the number of domestic violence-related referrals that day; from women's refuge organisations, giving the number of women using or seeking refuge places that day; and from the relationship counselling organisation Relate, giving the number of counselling sessions held on that day in which violence was mentioned as an issue.

Some analysis of reported victims and attackers was also carried out, where the required information was available. Based on partial figures, an estimated $81 \%$ of reports were from female victims attacked by male perpetrators. Not all the violence reported was intimate partner violence; some forces used a definition of domestic violence encompassing any violence taking place in the home. A separate analysis found that $86 \%$ of attacks by partners and former partners were carried out by male perpetrators against female victims. 
This brief sketch of the Domestic Violence Audit raises a number of questions. Firstly, the measurements produced by the Audit relate to incidence rather than prevalence: how much domestic violence took place in England and Wales, not how widespread it was. We cannot assume that those 1300 calls for police service came from 1300 different people, nor that there would not have any overlap between callers on one day and callers on the next.

The question of severity was also downplayed. The Audit dealt with police forces on the basis that "the force itself felt that the call reflected their own workload for whatever they defined as 'domestic violence'" (Stanko 2001: 219). This inevitably led to a very wide range of incidents being reported. Stanko refers only once to the severity of the incidents reported:

Injuries from domestic violence on 28 September include rape, cuts, stabbing, bleeding due to being kicked during pregnancy, 'throat slashed with a razor blade' and bruising to 'just' terror and intimidation.

(Stanko 2001: 219)

Stanko's ironic phrasing undercuts the idea of a scale of severity, suggesting that all domestic violence merits treating as severe: variations in severity are acknowledged only to be dismissed.

If the Audit was not organised around questions of prevalence or severity, the question of visibility was central. A key metric of the Audit was the proportion of the workload of the police and other agencies devoted to domestic violence. The Audit "explores the impact of domestic violence on a few public and voluntary services in the UK" (Stanko 2001: 217); on the day of the Audit, domestic violence accounted for "one in four crimes of violence" in the London area, and "one in 15" referrals to Victim Support in England (Stanko 2001:219,220; emphasis in original). 
The emphasis of the Audit is on domestic violence as a form of preventable suffering which is currently being overlooked or inadequately addressed. This is not to say that it is unknown. Stanko cites, and rejects, the perception that "most domestic violence is hidden from criminal justice scrutiny"; for the police and other agencies consulted, she argues, "domestic violence is not a hidden crime", but is "very visible in their day-to-day workloads" (Stanko 2001: 216, 223). If domestic violence suffers from inadequate visibility, the cause is a lack of public awareness of the work already being carried out by agencies such as the police.

At the same time, Stanko argues that "Women's Aid and Refuge are in contact with more women on a day-to-day basis than contact the police"; moreover, "Women's Aid, according to the 1996 British Crime Survey self-report study, are contacted by only 3 per cent of those who report domestic violence to crime survey researchers" (Stanko 2001:222). While these figures are not directly comparable, the inference is that even the figures produced by the Audit are likely to be inadequate. The lack of public awareness of the institutional visibility of domestic violence is compounded by the existence of a genuine 'dark figure' of domestic violence, representing an unseen population of victims who are not in contact with competent agencies.

These two distinct framings of victims of domestic violence begin from a shared assumption: that agencies' response to domestic violence produces domestic violence as a known problem. The data on domestic violence calls for service to the police set a baseline for the level of attention which domestic violence was already assumed to deserve; the Audit served to bring this existing valuation of domestic violence to public attention. The comparison with other sources of data, meanwhile, suggested that - whatever flaws they might have - the police figures were not an underestimation of the problem; revisions based on improved knowledge could only be upward. Fuller and better targeted agency interventions would produce a fuller picture of domestic violence - and one involving a higher number of victims. 
The Audit's lack of emphasis on questions of prevalence and severity can be understood in this context. Stanko notes that the Audit "demonstrated that it is possible to use a criminological imagination to raise the profile of an important issue", referring to it as "an innovative methodology to stimulate awareness about a serious social problem" and "a perfect tool for public awareness ... for the issue of domestic violence" (Stanko 2001: 224, 215, 217). The publicity given to the Audit, Stanko concludes, lodged the figure of 1300 calls per day in the public consciousness; "the public at large can no longer assume that domestic violence happens to 'others' without thinking about the person who rings the police for help somewhere in the UK each minute of every day" (Stanko 2001: 224). This point is underlined by the use made of an even higher figure. Other sources suggest that the number of calls to the police is between one third and one tenth of the true number of incidents of domestic violence; extrapolating, "we could say that an incident of domestic violence occurs in the UK every six to 20 seconds" (Stanko 2001: 222). One article cited in the context of the reception of the Audit states: "[e]very six seconds a woman in Britain is raped, stabbed or beaten by the man she lives with, according to a startling report out today." (Lawrence 2000)). The Audit - qualified by the "between one third and one tenth" estimate - supported the conclusion that between 4,000 and 13,000 domestic violence incidents took place in an average day, many of them relatively minor, $80-90 \%$ of them with female victims; it could not support the statement that over 14,000 women were victims of serious intimate partner violence every day. The citation of this article as an unproblematic example of positive press coverage adds to the impression that the aim of the Audit was less to measure the problem than to use a statistically-validated illustration of it as an intervention in public debate.

Stanko's approach was one of 'newsmaking criminology': not a fact-finding exercise but a reactive intervention in the media presentation of domestic violence. The audit was critical of existing definitions of domestic violence, which had led to understatement of the scope and scale of the problem; it was sceptical of the capacity of the criminal justice system to address the problem, or 
fully comprehend it, without the input of women's refuges and domestic violence activists; and it was partisan, framed by an identification with female victims of male violence.

\section{Begging, drugs and litter: the Anti-Social Behaviour Day Count}

Over the twenty-four hours from midnight on 10 September 2003, agencies with responsibilities relating to anti-social behaviour in England and Wales were asked to compile a report summarising all reported incidents of anti-social behaviour. The Anti-Social Behaviour Day Count was quantified by assigning each type of incident a typical cost, from which a total cost was estimated. It was concluded that "[a]nti-social behaviour recorded on the day of the count cost agencies in England and Wales at least $£ 13.5 \mathrm{~m}$; this equates to around $£ 3.4$ bn a year" (Home Office 2003). The conclusions of the Day Count, and the figure of $£ 3.4$ billion in particular, were cited in a subsequent Home Office publication (Home Office 2004:8-9), from which they entered the policy literature (e.g. National Audit Office 2006:8, House of Commons 2007: 3).

As with the Audit, the focus of the Day Count was on incidence: a total number of reports was given and then multiplied out by 250 to give a projected annual figure. The lack of attention to prevalence issues is striking: with data from across England and Wales, local concentrations of anti-social behaviour (or its reporting) might usefully have been analysed. Severity is also underplayed; instead, relatively trivial forms of behaviour are identified as sharing with more harmful forms the property of being 'anti-social', and hence identified as forming part of a single serious problem. The public face presented by the Day Count - as by the Audit - is of a single, serious, national problem, not to be disaggregated either by area or by severity.

There are a number of significant differences between the two exercises, relating to the agencies involved; the frame used to produce the survey data; the variability of the behaviours being observed; and the ascription of estimated financial costs. Firstly, as well as police forces, the Day 
Count involved local authorities and agencies such as registered social landlords and fire services. In all, over 1500 organisations contributed, from every Crime and Disorder Reduction Partnership area in England and Wales. This indicates a much broader conception of the agencies on the 'front line' of addressing anti-social behaviour than in the case of domestic violence.

This approach presents a risk of double-counting. With tallies of incidents as poorly-defined as 'noise' being submitted by a disparate set of agencies - no one of which had overall responsibility for responding to anti-social behaviour - there is no reason to assume that incidents were not reported more than once. The nature of the behaviours being counted also makes extrapolating to a full-year estimate problematic. For instance, in the case of 'vandalism' - the category with the highest estimated total cost - it seems highly unlikely that the 7,855 reports recorded for the period of the Day Count corresponded to 7,855 incidents of vandalism all of which took place on that day, and none of which would have been reported the following day if the exercise had been run continuously. In the words of the academics who derived the Day Count's costing methodology, "the count may reflect a 'stock' of problems rather than a 'flow' of those behaviours which happened on the day of the count" (Whitehead, Stockdale and Razzu 2003:7).

Secondly, the data produced by the Day Count was both more detailed and more unified than the data produced by the Audit. A standard typology was supplied by the Home Office, detailing sixteen types of anti-social behaviour: agencies were asked in effect to maintain sixteen distinct tallies (Home Office 2004; see below, Table 1). In effect, agencies were not asked to consider (to borrow Stanko's phrasing) whether the incidents reported were representative of their own workload for whatever they defined as 'anti-social behaviour", but whether they met the criteria for those behaviours classified by the Home Office as 'anti-social behaviour'.

Another effect of the questionnaire frame was to suggest that each individual agency had some responsibility for anti-social behaviour in all its forms, from drug dealing to litter. The Day Count 
effectively offered to define as well as to measure anti-social behaviour, and defined it as an issue to be addressed by all the agencies involved. The initial list of sixteen categories was reduced on publication to thirteen, with the amalgamation of 'prostitution' and 'kerb crawling' with 'sexual acts' and, rather more arbitrarily, of 'begging' with 'street drinking'. Even so, the thirteen categories covered a very broad range, and it is striking that each of the main types of agency reported at least one example of each of the main types of incident. For instance, 17 'hoax calls' were reported by housing associations and 42 incidents of 'prostitution, kerb crawling and other sexual acts' by local authority environmental health departments (Home Office 2004).

This approach imposed a double restriction on the agencies responding to the survey: respondents were instructed, in effect, to report any of the listed behaviours as anti-social behaviour (whatever their own view), but not to report any behaviour which they did regard as anti-social unless it was on the list. It is worth noting that the 2003/4 British Crime Survey - fieldwork for which was being conducted on the day of the Day Count - found that the most significant form of anti-social behaviour for its respondents was 'speeding traffic' (Wood 2004).

Table 1 List of behaviours to be included in Anti-Social Behaviour Day Count

\begin{tabular}{|l|l|}
\hline Type of behaviour & Behaviour \\
\hline Misuse of public space & Drug/substance misuse \& dealing \\
\cline { 2 - 2 } & Street drinking \\
\cline { 2 - 2 } & Begging \\
\cline { 2 - 2 } & Prostitution \\
\cline { 2 - 2 } & Kerb crawling \\
\cline { 2 - 2 } & Sexual acts \\
\hline & Abandoned cars \\
\hline
\end{tabular}




\begin{tabular}{|l|l|}
\hline \multirow{3}{*}{ Disregard for community } & Vehicle-related nuisance \\
& Noise \\
\cline { 2 - 2 } & Nowdy behaviour \\
\cline { 2 - 2 } & Hoax calls \\
\cline { 2 - 2 } & Animal related problems \\
\hline Acts directed at people & Intimidation/harassment \\
\hline Environmental damage & Criminal damage/vandalism \\
\cline { 2 - 2 } & Litter/rubbish \\
\hline
\end{tabular}

Source: Home Office 2004

Thirdly, as Table 1 illustrates, the behaviours to be summarised by the Day Count cover an extraordinarily wide range, from the specificity of 'hoax calls' to the imprecision of 'noise'. Some behaviours listed are highly serious in their impact, others trivial; some are everyday irritations, some criminal offences. There can be no guarantee that all the incidents reported under one heading were genuinely of the same type, or that they met a uniform threshold of significance. Indeed, the Home Office's guidelines on the behaviours falling under each heading positively encourages the proliferation of different interpretations. An incident of 'vehicle-related nuisance', for example, might be a life-endangering criminal offence ('setting vehicles alight') or a transient irritation ('cycling/skateboarding in pedestrian areas/footpaths') (Home Office 2004). Even the apparent precision of the themes listed in Table 1 rests on some fairly arbitrary distinctions. The category of 'misuse of public space', consisting mainly of transient activities which may cause offence when carried out in public, includes the long-term nuisance of 'abandoned vehicles'; 'environmental damage', implying activities with lasting ill-effects, includes 'litter/rubbish'. 
Table 2 organises the data presented in Home Office 2003 according to the thematic groups given in Home Office 2004.

Table 2 Counts and costs from the Anti-Social Behaviour Day Count

\begin{tabular}{|c|c|c|c|c|c|}
\hline & & \multicolumn{2}{|c|}{ Reports } & \multicolumn{2}{|c|}{ Cost } \\
\hline & & Total & as $\%$ & $\begin{array}{l}\text { Total } \\
(x 1000)\end{array}$ & as $\%$ \\
\hline \multirow[t]{6}{*}{ Misuse of public space } & Drugs & 2920 & $4.4 \%$ & $£ 527$ & $3.9 \%$ \\
\hline & Street drinking etc & 3239 & $4.9 \%$ & $£ 504$ & $3.7 \%$ \\
\hline & Prostitution etc & 1011 & $1.5 \%$ & $£ 167$ & $1.2 \%$ \\
\hline & Abandoned vehicles & 4994 & $7.6 \%$ & $£ 360$ & $2.7 \%$ \\
\hline & Vehicle nuisance & 7782 & $11.8 \%$ & $£ 1,361$ & $10.1 \%$ \\
\hline & Total & 19946 & $30.2 \%$ & $£ 2,919$ & $21.6 \%$ \\
\hline \multicolumn{6}{|c|}{ Disregard for community/ } \\
\hline \multirow{5}{*}{ personal wellbeing } & Rowdy behaviour & 5339 & $8.1 \%$ & $£ 995$ & $7.4 \%$ \\
\hline & Nuisance behaviour & 7660 & $11.6 \%$ & $£ 1,420$ & $10.5 \%$ \\
\hline & Hoax calls & 1286 & $1.9 \%$ & $£ 198$ & $1.5 \%$ \\
\hline & Animal problems & 2546 & $3.9 \%$ & $£ 458$ & $3.4 \%$ \\
\hline & Total & 22205 & $33.6 \%$ & $£ 4,065$ & $30.1 \%$ \\
\hline \multirow[t]{2}{*}{ Acts directed at people } & Intimidation etc & 5415 & $8.2 \%$ & $£ 1,983$ & $14.7 \%$ \\
\hline & Total & 5415 & $8.2 \%$ & $£ 1,983$ & $14.7 \%$ \\
\hline \multirow[t]{3}{*}{ Environmental damage } & Criminal damage & 7855 & $11.9 \%$ & $£ 2,667$ & $19.8 \%$ \\
\hline & Litter & 10686 & $16.2 \%$ & $£ 1,866$ & $13.8 \%$ \\
\hline & Total & 18541 & $28.0 \%$ & $£ 4,533$ & $33.6 \%$ \\
\hline
\end{tabular}


Source: author's elaboration from Home Office 2004. Line-item percentages may not add up to sub-total percentages, due to rounding.

There is wide variation in the numbers of reports and the estimated costs associated with each category. The two categories in the 'Environmental damage' group account for the largest single share of costs, at $33.6 \%$. By contrast, the five categories in the 'misuse of public space' group representing half of the categories in the original typology - are associated with only $21.6 \%$ of estimated costs. It should be noted that this type of calculation was not encouraged by the Home Office's own news release summarising the Day Count (Home Office 2003); rather than use thematic groups, this simply lists the individual categories of anti-social behaviour in descending order of number of incidents reported. The impression given was of anti-social behaviour taking place across the country, on a vast scale and in a kaleidoscopic profusion of forms.

The presentation of the data in the release does demonstrate that some types of behaviour are more common than others, with 'Litter/rubbish' (10,686 reports daily) clearly much more salient than the entire composite category of 'Prostitution/Kerb crawling/Sexual acts' $(1,011)$. However, any suggestion that this might suggest prioritisation of resources is undercut by the scale of the figures involved, the cost figures in particular. This assignment of estimated costs is the fourth novelty of the Day Count, and perhaps the greatest. The cost figures are all impressively high: even 'sexual' nuisances, at the bottom of the list, are assessed as costing agencies $£ 167,000$ per day, or $£ 42$ million per year. At the other end of the scale, a year's worth of litter is costed at $£ 466$ million. These figures are made especially striking by the citing of a single overall total - $£ 3,375$ million, generally cited in the form of '£3.4 billion'. It can be noted in passing that this figure is rounded up by $£ 25$ million: rounding error inflates the total by the equivalent of another week of criminal damage, or thirty weeks of sexual nuisance. 
These costs are based entirely on the costs associated with official responses to anti-social behaviour; while the desirability of finding a measure of the impact of the behaviour itself was recognised, no appropriate and available measure could be identified (Whitehead, Stockdale and Razzu 2003:15-21). This parallels the Audit's calculations of the relative salience of domestic violence work within the workload of the police and other responsible agencies. To arrive at the Day Count's estimated cost figures, the cost of different types of intervention was estimated, together with the likelihood of intervention at each level. For almost all types of anti-social behaviour, it is assumed that there is a $50 \%$ probability that no action will be taken, and hence that the only cost incurred will be that of processing a report; this is set at $£ 25$. (In the case of 'abandoned vehicles', the probability that no action will be taken is set at $70 \%$.) Based on estimates provided by practitioners, costs for taking action on 'abandoned vehicles' and 'hoax calls' are set at $£ 200$ and $£ 300$, giving estimated per-incident costings of $((£ 200 * 30 \%)+$ $(£ 25 * 70 \%))=£ 77.50$ and $((£ 300 * 50 \%)+(£ 25 * 50 \%))=£ 162.50$ respectively.

Response costs for all other types of incident are calculated using a more complex formula, using separate estimates of the cost and likelihood of low-, mid- and high-level responses as well as the $50 \%$ chance of a non-response. A low-level response here involves "a call-out together with some remedial action", a mid-level response "significant mediation/remediation" and a high-level response "significant and often legal intervention", such as application for an Anti-Social Behaviour Order (ASBO) (Whitehead, Stockdale and Razzu 2003:43). Costs for these levels of response are set at $£ 100, £ 500$ and $£ 5000$ respectively; the fixed $£ 25$ cost of processing the report is added to give costs of $£ 125, £ 525$ and $£ 5025$. Two types of incident are differentiated in terms of the typical profile of their responses (see Table 3). 'Criminal damage/vandalism' and 'intimidation/harassment' are classed as 'Type 1' incidents, more likely to receive a high-level response; 'Type 2' covers all other categories apart from 'hoax calls' and 'abandoned vehicles'. 


\begin{tabular}{|c|c|c|c|}
\hline \multirow[t]{2}{*}{ Response } & \multirow[t]{2}{*}{$\begin{array}{l}\text { Estimated } \\
\text { cost }\end{array}$} & \multicolumn{2}{|c|}{$\begin{array}{l}\text { \% of incidents } \\
\text { eliciting response }\end{array}$} \\
\hline & & Type 1 & Type 2 \\
\hline Report only & $£ 25$ & 50 & 50 \\
\hline Report \& low-level response & $£ 125$ & 25 & 29 \\
\hline Report \& mid-level response & $£ 525$ & 20 & 20 \\
\hline Report \& high-level response & $£ 5025$ & 5 & 1 \\
\hline
\end{tabular}

Source: Home Office 2004

The result of these calculations is that an average base cost of $£ 400$ is proposed for 'Type 1' incidents, and $£ 204$ for 'Type 2 ' incidents. For reasons which are not explained, the published Day Count uses lower estimates: cost figures range from $£ 156$ to $£ 194$ for Type 2 incidents, while the two categories of Type 1 incidents are costed at $£ 340$ (criminal damage) and $£ 366$ (intimidation). The two 'Type 1' categories account for $20.1 \%$ of all reports; thanks to the higher unit cost estimate, they make up $34.5 \%$ of estimated costs. 'Type 2 ' incidents account for $70.4 \%$ of reports and $61.4 \%$ of estimated costs; the remaining $9.5 \%$ of reports and $4.1 \%$ of estimated costs are accounted for by 'Hoax calls' and 'Abandoned vehicles'.

The calculations underlying the derived costings are heavily skewed by the use of an upper value of $£ 5025$, nearly ten times the value assigned to the next category and over 200 times the value assigned to the lowest. This makes the calculations highly sensitive to small changes in the distribution of incidents between categories. $76 \%$ of the cost of 'Type 2 ' incidents and $89 \%$ of the cost of 'Type 1' incidents derives from the estimated cost and likelihood of mid- and high-level responses; minor changes to these two estimates would change the calculated unit cost 
significantly. For instance, assuming that $4 \%$ rather than $5 \%$ of 'Type 1 ' incidents received a 'high-level' response, and $21 \%$ rather than $20 \%$ a 'mid-level' response, would give a unit cost of $£ 355$ rather than $£ 400$. Given that the total cost figure was arrived at by multiplying the calculated unit cost by the count of 13,270 'Type 1' reports, while the full-year figure was calculated by multiplying this figure by 250 , this small adjustment would produce a change of around $£ 130,000,000$ in the estimated yearly cost - nearly $4 \%$ of the estimated total.

The extreme malleability of these cost estimates suggests that it would have been preferable to remove the 'high-level response' from calculations. This would effectively have eliminated the difference between 'Type 1' and 'Type 2 ' incidents, while cutting the cost of both to $£ 155$ (and cutting the estimated annual cost of anti-social behaviour by a third). It is also worth noting that the formula used to estimate the crucial number of 'high-level responses' may err on the high side: the Day Count's costings imply that nearly 300,000 high-level responses would take place over a year (166,000 in response to Type 1 incidents, 132,000 to Type 2). In 2005, the peak year for ASBO applications, a little over 4,000 ASBOs were granted in the whole of England and Wales. Moreover, nearly $70 \%$ of those were "criminal ASBOs", granted in conjunction with a criminal sentence; the figure for non-criminal ASBOs was 1,277 (Home Office 2011).

Like the Audit, the Day Count also seems to have been designed to promote intolerance of the underlying phenomenon - and hence to lead in future to higher levels of reporting. The Home Office notes that "[i]t is recognised that a large proportion of anti-social behaviour is not reported due to apathy, tolerance of the behaviour or fear of repercussions amongst members of the public, or because people do not know where to report the problem" (Home Office 2004: 10). (No source is given for this statement.) Elsewhere, we read that incidents may not be reported because "the public ... will tolerate behaviour and not report it until it gets to a critical and intolerable stage" (Home Office 2004: 18). These references to apathy and tolerance are curious, given that the legal definition of anti-social behaviour hinges on behaviour "that caused or was 
likely to cause harassment, alarm or distress" (quoted in Home Office 2004: 3). The argument seems to be that, once anti-social behaviour has been identified as a problem (based on the alarm and distress that it typically causes), it can be assigned a consistent definition by the agencies responsible for dealing with it. This disengages the phenomenon from the public reaction which initially created the problem. Not all that causes alarm and distress is anti-social behaviour: anyone suffering alarm or distress as a result of behaviours not listed in Table 1 (speeding traffic, perhaps) is suffering from something other than anti-social behaviour. On the other hand, not all anti-social behaviour causes distress or alarm: drug use may be met with apathy or even tolerance, but this reaction is inappropriate and should be discouraged.

As we have seen, the Day Count follows the Domestic Violence Audit in its single-minded focus on incidence on the national level: like the Audit, it brackets questions of prevalence and downplays questions of severity, tending instead to 'level up' minor forms of anti-social behaviour. It has a similar goal - raising awareness of anti-social behaviour rather than generating detailed information about it - and a similar focus on visibility, framing the problem through its institutional response while also suggesting the existence of an unreported 'dark figure'. In both cases it is suggested that the dark figure is made up partly of behaviour which is known but, mistakenly, tolerated. Where the Day Count differs from the Audit is in quantifying agencies' responses through estimated monetary costs. This approach is highly functional, promoting 'levelling up' and increasing visibility, in particular by producing a dramatic final cost figure.

Like the Audit, the Day Count was reactive, in the sense that anti-social behaviour was already a current issue: the Anti-Social Behaviour Unit was set up in January 2003; what became the Anti-Social Behaviour Act 2003 was put before Parliament in March. The Day Count was critical, in the sense of diverting media attention away from serious criminal offences and focusing on behaviours which were within the law. The Day Count was predicated on scepticism about the capacity of the criminal justice system to control the harms of anti-social behaviour, 
tending to promote a much broader mobilisation. Lastly, the Day Count was plainly partisan, siding with those who believe themselves to be victims of anti-social behaviour.

\section{The production of anti-social behaviour: making reactionary news?}

In terms of method, the Audit and the Day Count both match Barak's description of 'newsmaking criminology'. Other similarities between the two can be identified. In both cases, the end result of the intervention was the consolidated public identification of a neglected type of offence domestic violence and anti-social behaviour, respectively. In both cases, the identification of an un- or under-recognised offence goes along with the identification of victims who had been given inadequate support and offenders who had been acting with impunity, as well as a setting (the home in the case of the Audit, urban communities in the case of the Day Count) which is disrupted by the offending behaviour in ways which had been overlooked.

Another similarity is that both exercises involved aggregating diffuse behaviours and giving them a single definition. While both domestic violence and anti-social behaviour can take extreme and directly harmful forms, they also take place in the form of incidents which are not immediately or obviously criminal. This is what a Labour Party discussion paper on anti-social behaviour called 'chronic crime': "where the offending behaviour is chronic and persistent, where the separation of incidents may lack forensic worth, where it is the aggregate impact of criminal behaviour which makes it intolerable" (Labour Party 1995; quoted in MacDonald 2006: 188).

In order to be grasped by the criminal justice system, the low-level behaviours constituting 'chronic' crime needed to be perceived as such, making it appropriate to treat what may be an individually trivial incident as seriously as the aggregate phenomenon requires. Both the Audit and the Day Count can be understood in these terms. The diffuseness and cumulative impact of harassment, and of some behaviours which could be classed as domestic violence, posed 
difficulties for campaigners wishing to bring them to light: while an individually trivial incident might have a huge effect on the victim because of its relation to earlier incidents, quantitative measures would only be able to 'see' the incident as an example of a class of trivial incidents.

The Audit's solution to the problem of aggregation and cumulative effect is twofold. On one hand, the institutional focus of the Audit suggests a threshold of seriousness - each incident counted was serious enough to warrant calling the police. On the other, cumulative effect is evoked by the persistent stress on the sheer number of domestic assaults happening day in, day out ("an incident of domestic violence ... every six to 20 seconds"). This effectively produces the impression of a phenomenon which should not be granted any further tolerance, however trivial any individual example might seem. In this respect the looseness of the Audit's definitional procedure worked in its favour, producing the impression of a continuum of violent behaviour: minor forms of domestic violence could be seen as different only in degree from the most serious forms.

The Day Count's cumulation of incidents and costs, together with the astronomical projected annual figures, produced a similar impression of an intolerably vast number of offensive incidents. The figures suggest that the problem of anti-social behaviour is already out of hand: it might once have been reasonable to overlook a single incident of 'rowdy behaviour', but not - the Day Count suggests - in a world where such behaviour costs the government three billion pounds per year. A significant difference is the Day Count's use of a pre-defined survey frame. Fly-tipping, indecent exposure and cycling on the pavement (among much else) are classified as 'anti-social behaviour' by definitional fiat: these are the behaviours to be counted as anti-social behaviour, because this is the agreed list of what counts as anti-social behaviour.

The Audit and the Day Count were both successful exercises in the production of knowledge; the question of the effectiveness of 'newsmaking criminology' can be answered in the affirmative. They both produced and publicised awareness of their subject area, considered as a social 
problem which public agencies were already addressing but not adequately controlling. Both interventions were circular by design: they aimed not to produce an accurate once-for-all figure of the scale of the problem but to promote awareness of it, leading in turn to lower tolerance, higher levels of reporting and, ultimately, higher recorded levels of domestic violence or anti-social behaviour. These developments would in turn promote pressures for higher levels of service provision and for still lower levels of tolerance.

The power to define behaviours as criminal is an example of Lukes's second dimension of power, which relates to "ways in which decisions are prevented from being taken on potential issues over which there is an observable conflict of (subjective) interests" (Lukes 1974: 20). To classify a behaviour as criminal is to remove it from the agenda of political debate. The case studies suggest that 'newsmaking criminology' can make a significant contribution to agenda-shaping struggles over how actions are defined or unacceptable and whose interests are advanced in doing so.

The Audit can be situated within a broader movement to heighten awareness of domestic violence and to empower its victims to demand an official response. Linking this example of 'newsmaking criminology' to struggles for emancipation and social justice is unproblematic. The politics of the Day Count are more murky. As we have seen, the Day Count produced knowledge of a defined set of behaviours as anti-social behaviour. The then Home Office minister Beverley Hughes had acknowledged the fluidity of the concept of anti-social behaviour in June 2003:

In one area it's young people causing problems on the street, in another it's noisy neighbours or abandoned cars. In one town centre it's street drinking and begging, in another it's prostitution.

(Hughes 2003) 
The implication is not that begging, prostitution or rowdy young people are only found in certain areas, but that there are only certain areas in which these phenomena amount to anti-social behaviour. By implication, there may be wide variations in the activities which are regarded as anti-social, and in the degree to which any one activity is seen as anti-social. This was the context within which the Day Count intervened, helping to produce a public consciousness of those behaviours which should be denounced and policed as anti-social.

Anti-social behaviour is defined in law by section 1(1) of the Crime and Disorder Act 1998, setting out the eligibility criteria for an ASBO. The criteria are not demanding: anti-social actions do not need to be serious in their impact, repeated over time, or deliberately undertaken; nor must distress actually be caused. What the law does stipulate is anti-social behaviour cannot include "any act of the defendant which he shows was reasonable in the circumstances". "Every application for an ASBO ... is premised upon a decision that the defendant's behaviour occurs in a context in which the attitude it manifests is in some way unreasonable in contrast to the myriad other behaviours that would also meet the criteria of s.1(1)." (Ramsay 2004:918-9).

To geuninely assess what is and isn't "reasonable in the circumstances" in any given case would depend on a full assessment of those circumstances. A prostitute 'anti-socially' soliciting trade may be trying to earn the price of a school uniform; a driver speeding down a residential street may be trying to save five minutes' drinking time. The loose phrasing insisted on by the 1998 Act's drafters (Edwards 2011) left it open to the wide-ranging uses documented by Macdonald (2006), but also created a space for nuanced and critical assessments; this was closed down by the Day Count's production of knowledge of anti-social behaviour. The Day Count suggests that certain acts should invariably be considered "anti-social", even if they are arguably justified and cause no distress, while others should not be considered as "anti-social" even if they cause distress and are not justified. What is problematic about street drinking, for example is not that it causes 
distress, or even that it is experienced as intolerable, but that it is in itself a form of anti-social behaviour - and as such should not be tolerated, and should be experienced as causing distress.

It is worth recalling that the original formulation of "Broken Windows" policing suggested that the police should address "the fear of being bothered by disorderly people" (a category including "panhandlers, drunks, addicts, rowdy teenagers, prostitutes, loiterers, the mentally disturbed") (Wilson and Kelling 1982: 30); if one group is afraid of the other, the solution is to control the second group. What is at issue is a defensive reassertion of control over social space. The acts which the Day Count puts in the frame of anti-social behaviour are typically - in some cases by definition - associated with 'disorderly people'; the Day Count helps to construct those groups as "internal outsiders", people for whom the role of law enforcement is simply to "get them off the street and out of the picture" (Currie 1988:281).

\section{Conclusion}

Both the Audit and the Day Count were exercises in newsmaking criminology. They were reactive interventions in a national political debate; they were critical, redirecting the attention of the media towards behaviours not currently considered criminal; they were sceptical of the capacity of the criminal justice system to control this new category of crime; and their partisanship cannot be doubted. They both identified a new - or under-recognised - type of offending, highlighting continuities and similarities among multiple disparate behaviours; this went along with the identification of a setting where the incidence of this type of offending had been overlooked, as well as an under-supported victim population and an under-sanctioned group of offenders. However, the techniques of newsmaking criminology, which served progressive and empowering ends in the case of the Audit, were put to broadly reactionary uses in the Day Count. 
This suggests that the methods of 'newsmaking criminology' are a politically neutral toolset and that they can be used to produce reactionary as well as progressive forms of public knowledge. This in turn raises the question of how 'newsmaking' projects aiming to serve emancipatory ends can guard against producing divisive and reactionary forms of knowledge. While the government's involvement in the Day Count was substantial and significant, avoiding contamination by government sponsorship would be a counsel of despair; in any case, the vital police contribution to the Audit suggests that an effective progressive intervention can take place with substantial official involvement. It could be argued that the particular type of 'newsmaking' being undertaken in these case studies - the identification of an unseen offence with overlooked victim and offender populations - is inherently liable to lend itself to divisive and reactionary conclusions; however, here again the evidence of the Audit suggests that a reactionary drift is not inevitable. Conversely, the difference between the two exercises could be located in the Audit's relationship with the contemporary women's movement: the Day Count, by contrast, had roots in local authority managerialism, more specifically the 1990s debate about local authority responses to persistent low-level criminality in social housing (Burney 2004). Arguably anti-social behaviour had from the outset been framed in terms of identifying one group of working-class people - initially, one group of social housing tenants - as a source of problems for another. It was this, partly artificial, social cleavage which the newsmaking intervention of the Day Count worked to consolidate and publicise, with reflexive effects on criminology - as witness the continuing salience of anti-social behaviour as a research topic - as well as on public policy.

Perhaps the only firm conclusion is negative: that the 'newsmaking criminology' template, of itself, is not proof against the production of reactionary forms of knowledge and the reinforcement of social division. This in turn suggests that criminologists working with the 'newsmaking' framework should ask themselves, not only how their intervention might serve socially progressive ends, but in what social cleavage or conflict the intervention is situated and to 
what social movement, if any, it responds. Reflexivity cannot be entirely self-generated; the most effective auditing is provided by accountability to a genuine social movement.

\section{References}

Barak, G. (1988). Newsmaking criminology: Reflections of the media, intellectuals, and crime. Justice Quarterly 5(4), 565-587.

Barak, G. (1994/1995). A response to the editors' call for dialogue: Time for an integrated critical criminology. The Critical Criminologist 6\&7: 3-6.

Barak, G. (2007). Doing newsmaking criminology from within the academy. Theoretical Criminology 11(2), 191-207.

Burney, E. (2004). Talking Tough, Acting Coy: What Happened to the Anti-Social Behaviour Order? Howard Journal 41(5): 469-484.

Currie, E. (1988). Two visions of community crime prevention. In T. Hope and M. Shaw (Eds.), Communities and Crime Reduction (pp. 280-286). London: HMSO.

Edwards, P. (2011). Broken Windows, broken promises: from the CSO to the ASBO. Given at York Deviancy Conference, 1 July.

Garland, D. and Sparks, R. (2000). Criminology, social theory and the challenge of our times. British Journal of Criminology 40(2), 189-204

Home Office (2003). The one day count of anti-social behaviour. London: The Stationery Office. Home Office (2004). Defining and measuring anti-social behaviour, HODPR 26. London: The Stationery Office.

Home Office (2011). Anti-Social Behaviour Order Statistics-England and Wales 2010. London: The Stationery Office.

House of Commons (2007). Tackling Anti-Social Behaviour, HC246. London: The Stationery Office. 
Hughes, B. (2003). Developing Locally-Led Responses to Anti-social Behaviour, speech to New Local Government Network, June 10.

Labour Party (1995). A Quiet Life: Tough Action on Criminal Neighbours. London: Labour Party. Lawrence, L. (2000). Shock toll of women victims. Daily Mail, 25 October.

Lukes, Steven (1974). Power: A Radical View. London: Macmillan.

MacDonald, S. (2006). A Suicidal Woman, Roaming Pigs and a Noisy Trampolinist: Refining the ASBO's Definition of 'Anti-social Behaviour'. Modern Law Review 69(2): 183-213.

National Audit Office (2006). Tackling Anti-social Behaviour, HC 99 2006-2007. London: The Stationery Office.

Pavlich, G. (1999). Criticism and Criminology: In Search of Legitimacy. Theoretical Criminology $3(1), 29-51$.

Ramsay, P. (2004). What is anti-social behaviour?. Criminal Law Review: 908-25.

Smart, C. (1992). Feminist approaches to criminology or Postmodern Woman meets Atavistic Man. In Gelsthorpe, L. and Morris, A. (Eds.), Feminist perspectives in criminology (pp. 70-84). Milton Keynes: Open University

Stanko, E. (2001). The Day to Count: Reflections on a Methodology to Raise Awareness about the Impact of Domestic Violence in the UK. Criminal Justice 1(2): 215-26.

Thomas, J. and O'Maolchatha, A. (1989). Reassessing the critical metaphor: An optimistic revisionist view. Justice Quarterly 6(2): 143-172.

Whitehead, C., Stockdale, J. and Razzu, G. (2003). The Economic and Social Costs of Anti-social Behaviour: A Review. London: London School of Economics.

Wilson, J. Q. and Kelling, G. L. (1982). Broken Windows: The Police and Neighborhood Safety. Atlantic Monthly 127: 29-38.

Wood, M. (2004) Perceptions and experience of antisocial behaviour: Findings from the 2003/4 British Crime Survey, Home Office Online Report 49/04. London: The Stationery Office. 